\title{
Tilt error in cryospheric surface radiation measurements at high latitudes: a model study
}

\author{
Wiley Steven Bogren ${ }^{1, a}$, John Faulkner Burkhart ${ }^{2,3}$, and Arve Kylling ${ }^{1}$ \\ ${ }^{1}$ NILU - Norwegian Institute for Air Research, P.O. Box 100, 2027 Kjeller, Norway \\ ${ }^{2}$ Department of Geosciences, University of Oslo, Oslo, Norway \\ ${ }^{3}$ Sierra Nevada Research Institute, University of California, Merced, California, USA \\ anow at: NIBIO - Norwegian Institute of Bioeconomy Research, P.O. Box 115, 1431, Ås, Norway \\ Correspondence to: John Faulkner Burkhart (john.burkhart@geo.uio.no)
}

Received: 17 June 2015 - Published in The Cryosphere Discuss.: 18 August 2015

Revised: 3 March 2016 - Accepted: 4 March 2016 - Published: 15 March 2016

\begin{abstract}
We have evaluated the magnitude and makeup of error in cryospheric radiation observations due to small sensor misalignment in in situ measurements of solar irradiance. This error is examined through simulation of diffuse and direct irradiance arriving at a detector with a cosine-response fore optic. Emphasis is placed on assessing total error over the solar shortwave spectrum from 250 to $4500 \mathrm{~nm}$, as well as supporting investigation over other relevant shortwave spectral ranges. The total measurement error introduced by sensor tilt is dominated by the direct component. For a typical highlatitude albedo measurement with a solar zenith angle of $60^{\circ}$, a sensor tilted by 1,3 , and $5^{\circ}$ can, respectively introduce up to $2.7,8.1$, and $13.5 \%$ error into the measured irradiance and similar errors in the derived albedo. Depending on the daily range of solar azimuth and zenith angles, significant measurement error can persist also in integrated daily irradiance and albedo. Simulations including a cloud layer demonstrate decreasing tilt error with increasing cloud optical depth.
\end{abstract}

\section{Introduction}

In situ observations of the albedo of snow-covered surfaces are important for a variety of purposes. As part of a manned measurement program or campaign, they allow high spectral resolution and correlation to physical properties of the snowpack (Aoki et al., 2000). When collected by an automatic weather station (AWS) or tower, albedo measurements contribute to a larger suite of energy balance and/or weather observations. In addition, in situ albedo measurement cam- paigns are necessary for validating remotely sensed observations of surface albedo (Stroeve et al., 1997, 2013; Liang, 2001; Klein and Stroeve, 2002; Svacina et al., 2014) as well as improving and assessing results of climate models (Van Angelen et al., 2012).

The climate modeling community has previously called for an accuracy of 0.02 or better from albedo data sets used as model input (Sellers et al., 1995). Since ground measurements should be of higher accuracy than the data sets they validate, potential measurement errors of 0.01 or larger are significant and undesirable. Global albedo measurement may be made by two pyranometers measuring the down- and upwelling global irradiance. This is usually the method preferred for unmanned AWSs in remote locations. Alternatively a pyrheliometer may be used to measure the direct component and a shaded pyranometer the diffuse component. Combining the two gives the global irradiance. However, instruments with moving parts are generally not suitable at unmanned remote locations due to power limitations and lack of regular maintenance. An alternative and elegant alternative with no moving parts does exist for simultaneous measurement of the diffuse and direct radiation components (e.g., Long et al., 2010), but these instruments have yet to be commonly deployed.

Error sources such as shading of the surface by the sensor setup, slope of the surface, accurate calibration of the sensors, and characterization of the sensor's angular response function are commonly recognized and addressed (e.g., Grenfell et al., 1994; Perovich et al., 2002; Gardner and Sharp, 2010; Nicolaus et al., 2010). The error due to tilting 
of the sensor is rarely discussed. In perhaps the most thorough uncertainty analysis of solar irradiance measurements, Bernhard and Seckmeyer (1999) estimated that the optics of an irradiance meter may be leveled to a standard uncertainty of $\pm 0.1^{\circ}$, resulting in $0.2 \%$ uncertainty in the irradiance for a solar zenith angle of $60^{\circ}$ and a wavelength of $400 \mathrm{~nm}$. However, Stroeve et al. (2006) estimate the uncertainty in the AWS in situ albedo to be 0.035 . The AWS instruments lack leveling certainty to reliably gauge sub-diurnal albedo variability and in the ablation zone, leveling errors up to $40^{\circ}$ have been experienced. Stroeve et al. (2001) acknowledge that "the primary source of error in the measurement of surface albedo is instrument level". However, they do not quantify this error for the instrument they use in their intercomparison between in situ and Advance Very High Resolution Radiometer (AVHRR)-derived surface albedo over Greenland. Other errors include imperfect cosine response, frost, and reflections/shadows.

In manned campaign settings, sensors are often removed from their mounting for safe transport to and from the measurement site. In order to achieve level irradiance measurements, the sensors must be mounted in proper orientation quickly and firmly, and the stand itself must be positioned and leveled with minimal disturbance to the snowpack beneath the sensors. For permanent installations, wind and changes in surface conditions (melting snow and ice) may change the sensor orientation. Achieving level measurement is even more difficult on a moving platform in turbulent conditions, such as a boat, ice buoy, or small aircraft. Fortunately, such platforms often maintain an excellent record of orientation which can be used to assess uncertainty in irradiance and albedo measurements, and when necessary correct them to some degree.

Several studies recognize the tilt error problem and some propose strategies to correct for tilt errors. Some of these studies are listed in Table 1. The tilt correction methods include correction for level errors during site visits (Stroeve et al., 2001); averaging over $24 \mathrm{~h}$ (Stroeve et al., 2013); correction of direct beam contribution to the irradiance (Van As, 2011); model for tilt correction based on independent leveled measurements (Weiser et al., 2015); retrospective, iterative, geometry-based (RIGB) analysis to retrieve tilt and rotation by comparing simulations and measurements for temporal shifts (Wang et al., 2015).

The intention of this study is to present the first thorough quantification of the potential error in irradiance measurements from sensor orientation, considering separately the error in measured diffuse and direct irradiance, and the combined total error in tilted sensor measurements. Our aim is to highlight the potential significance of an error term that is relatively straightforward to mitigate, and thus more readily achieve stated objectives of making reflectance measurements with an accuracy of better than 0.02 in order to provide useful validation data for remote sensing platforms. The error is calculated by using a radiative transfer model to simulate the radiance field over a surface with a spectral albedo representative for snow. The radiance field is used together with an instrument leveling model to simulate the effect of leveling errors on measured irradiance as described in Sect. 2. The results from the simulations are presented in Sect. 3. In Sect. 4 we discuss the limitations and implications of these results, as well as recommendations for addressing this large source of measurement uncertainty. Conclusions are given in Sect. 5.

\section{Methods}

The surface albedo $A(\lambda)$ at wavelength $\lambda$ is defined as the ratio between the upwelling, $E^{\uparrow}(\lambda)$, and downwelling, $E^{\downarrow}(\lambda)$, irradiances at the surface:

$A(\lambda)=\frac{E^{\uparrow}(\lambda)}{E^{\downarrow}(\lambda)}$.

The global albedo $A_{\mathrm{g}}$ is defined as

$A_{\mathrm{g}}=\frac{\int_{0}^{\infty} E^{\uparrow}(\lambda) \mathrm{d} \lambda}{\int_{0}^{\infty} E^{\downarrow}(\lambda) \mathrm{d} \lambda}$,

and the albedo measured by typical shortwave irradiance detectors:

$A_{\mathrm{SW}}=\frac{\int_{250}^{2500} E^{\uparrow}(\lambda) \mathrm{d} \lambda}{\int_{250}^{2500} E^{\downarrow}(\lambda) \mathrm{d} \lambda}$.

Furthermore, we calculate the ultraviolet (UV) and visible albedo by integrating between 250 and $900 \mathrm{~nm}$.

$A_{\text {vis }}=\frac{\int_{250}^{900} E^{\uparrow}(\lambda) \mathrm{d} \lambda}{\int_{250}^{900} E^{\downarrow}(\lambda) \mathrm{d} \lambda}$

The daily integrated albedo is calculated following Stroeve et al. (2006):

$A_{i}=\frac{\sum E^{\uparrow}}{\sum E^{\downarrow}}$,

where the sum is over $24 \mathrm{~h}$. Here and below we omit the $\lambda$ dependence for simplicity, but, unless otherwise noted, it is implicitly included in all relevant quantities.

The upwelling and downwelling irradiances are defined as

$$
\begin{aligned}
& E^{\uparrow}=\int_{0}^{2 \pi} \mathrm{d} \phi \int_{-\pi / 2}^{0} L(\theta, \phi) \cos \theta \sin \theta \mathrm{d} \theta \\
& E_{\mathrm{h}}^{\downarrow}=E_{0}^{\mathrm{sur}} \cos \theta_{0}+\int_{0}^{2 \pi} \mathrm{d} \phi \int_{0}^{\pi / 2} L(\theta, \phi) \cos \theta \sin \theta \mathrm{d} \theta,
\end{aligned}
$$

where $L(\theta, \phi)$ is the radiance for polar angle $\theta$ and azimuth angle $\phi$, and $E_{0}^{\text {sur }}$ is the direct solar flux at the surface. The 
Table 1. Examples of tilt correction strategies.

\begin{tabular}{|c|c|c|c|}
\hline Reference & Instrument & Tilt correction & Comments \\
\hline Long et al. (2010) & SPN1 & $\begin{array}{l}\text { Use measured diffuse } \\
\text { and direct radiation }\end{array}$ & \\
\hline Oerlemans and Klok (2002) & AWS & No correction & $\begin{array}{l}\text { Tilt assumed to be } \\
\text { parallel to surface }\end{array}$ \\
\hline Stroeve et al. (2001) & AWS & $\begin{array}{l}\text { Correct level error } \\
\text { during site visits }\end{array}$ & \\
\hline Stroeve et al. (2013) & AWS & $24 \mathrm{~h}$ mean & Miss daily albedo variability \\
\hline Van As (2011) & AWS & Direct beam & \\
\hline Van den Broeke et al. (2004a) & AWS & $24 \mathrm{~h}$ mean & Miss daily albedo variability \\
\hline Weiser et al. (2015) & AWS+BSRN & $\begin{array}{l}\text { Model- and } \\
\text { measurement-based }\end{array}$ & $\begin{array}{l}\text { Requires additional } \\
\text { leveled instrument. }\end{array}$ \\
\hline Wang et al. (2015) & AWS & Geometry-based & \\
\hline
\end{tabular}

AWS: automated weather station. BSRN: Baseline Surface Radiation Network. SPN1: total/diffuse radiometer

subscript $\mathrm{h}$ in $E_{\mathrm{h}}^{\downarrow}$ indicates that the irradiance is calculated with respect to the horizontal. Equation (1) implies a leveled instrument with perfect cosine response. For an unleveled instrument the downwelling irradiance is

$E_{\mathrm{t}}^{\downarrow}=E_{0}^{\text {sur }} \cos \left(\theta_{0}-\theta_{\mathrm{t}} \cos \phi_{\mathrm{t}}\right)+\int_{0}^{2 \pi} \mathrm{d} \phi \int_{\Delta \theta}^{\pi / 2+\Delta \theta}$

$L(\theta, \phi) \cos \theta \sin \theta \mathrm{d} \theta$,

where $\Delta \theta$ is the angle the instrument is tilted, $\theta_{\mathrm{t}}=\pi / 2+\Delta \theta$, and $\phi_{\mathrm{t}}$ is the relative azimuth angle of the sensor tilt to the sun. The subscript $t$ thus refers to tilted quantities.

The difference between $E_{\mathrm{h}}^{\downarrow}$ and $E_{\mathrm{t}}^{\downarrow}$ will impact measurement of the albedo, assuming negligible tilt error effect in $E^{\uparrow}$. To assess this impact, simulations of the radiance $L(\theta, \phi)$ were carried out for different solar angles and measurement geometries.

\subsection{Radiative transfer model}

The uvspec program from the libradtran software package (Mayer and Kylling, 2005; Emde et al., 2015) was used to simulate the radiance $L(\theta, \phi)$. Trace gas concentrations were taken from the subarctic summer atmospheric profile (Anderson et al., 1986). The surface was assumed to be Lambertian and a spectral surface albedo representative for pure snow was used (Wiscombe and Warren, 1980) unless otherwise noted. For both global (250-4500 nm) and shorter (250$900 \mathrm{~nm}$ and $250-2500 \mathrm{~nm}$ ) spectral intervals the spectral resolution and dependence of trace gases were taken from the correlated-k distribution of Kato et al. (1999). Aerosol was not included. Clouds were included for sensitivity tests and their impact is discussed in Sect. 3.4. The 1-D radiative transfer equation is solved by the DIScrete-Ordinate-method Radiative Transfer (DISORT) solver with 32 streams in pseudospherical geometry (Stamnes et al., 1988; Buras et al., 2011;
Dahlback and Stamnes, 1991). The radiative transfer model computes both the direct and the multiple scattered diffuse radiation, $L(\theta, \phi)$. In these numerical experiments the angular resolution of the latter is at quarter degree resolution for both azimuth $(\theta)$ and polar $(\phi)$ angles. The libradtran radiative transfer model has been compared and validated against both other models and measurements. A summary of these are given in Mayer and Kylling (2005).

\subsection{Tilt calculation}

The angres tool from the libradtran package was used to simulate the response of a tilted and rotated irradiance sensor. The angres tool takes as input a radiance field $(L(\theta, \phi))$ and an angular response function representing the instruments angular response. The integral in Eq. (8) is then performed for the tilted and rotated response function. The sensor was rotated from 0 to $180^{\circ}$ relative azimuth at $2.5^{\circ}$ intervals. The rotations were performed for sensor tilts of 1,3 , and $5^{\circ}$.

For all simulations the sensor angular response was modeled as a perfect cosine function, although it is well known that real angular responses of irradiance meters do deviate from a true cosine response (Bais et al., 1998).

The angres tool combined with output from uvspec have been successfully compared against measurements for leveled and extremely tilted $\left(90^{\circ}\right)$ sensors by Mayer and Kylling (2005, Fig. 13).

\subsection{Sensitivity experiments}

The simulations cover a range of solar zenith angles from noon $\left(0^{\circ}\right)$ to near-dusk $\left(80^{\circ}\right)$. As the majority of snow albedo measurements are made in polar regions, focus was on solar zenith angles greater than $50^{\circ}$.

Three sensitivity experiments were performed, aimed at quantifying sensitivity of the simulated error to constant surface albedo, and to the integrated spectral ranges. For the 

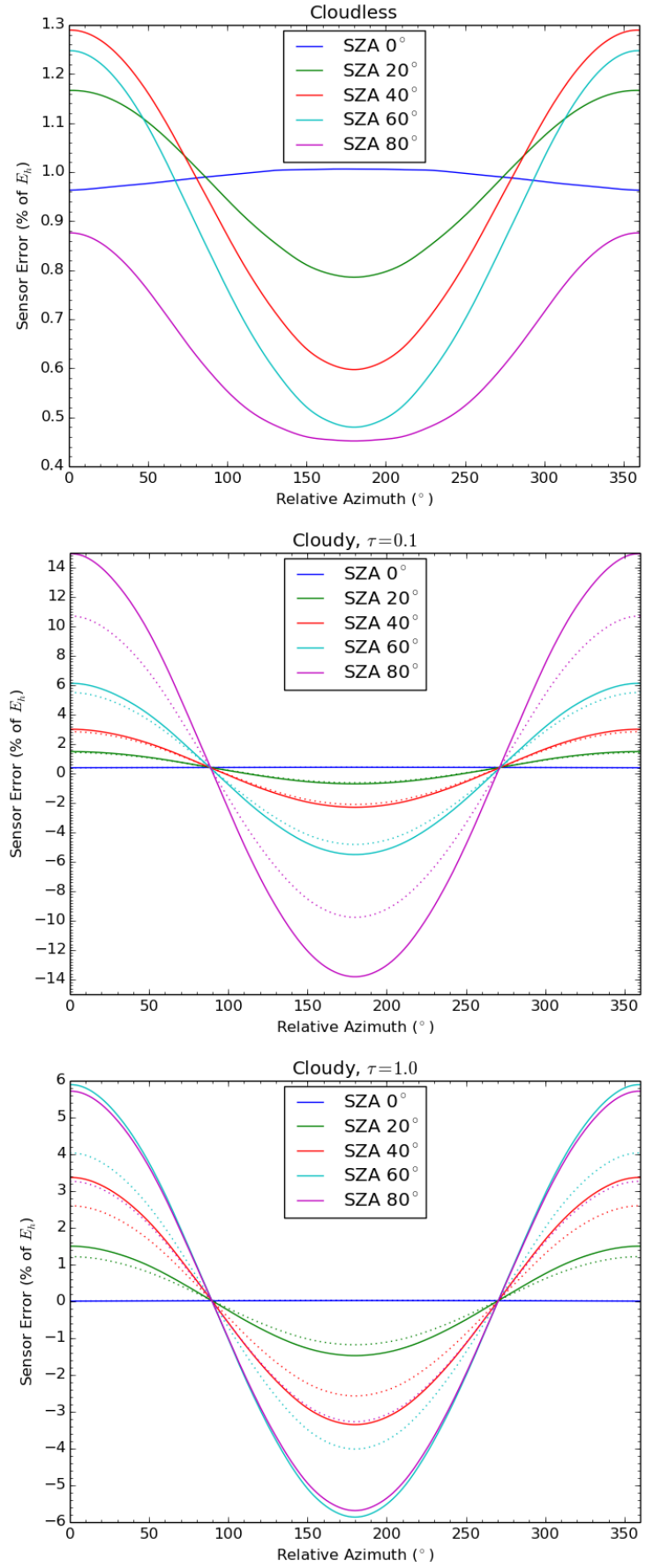

Figure 1. Simulated error in global diffuse irradiance, $\eta_{\text {dif }}$, for a cosine-response irradiance sensor tilted $3^{\circ}$. One cloudless (top) and two cloudy cases are shown. In the middle and bottom plots, solid (dotted) lines denote liquid (ice) water cloud results. Note different scale on $y$ axes.

first experiment, the surface albedos of 0.9 and 0.2 were considered. For the second experiment, spectral integration was performed over wavelength bands chosen to match approximately the calibrated response of typical visible and com- plete shortwave irradiance detectors, covering, respectively 250 to $900 \mathrm{~nm}$ and 250 to $2500 \mathrm{~nm}$. For the third experiment a homogeneous cloud layer with increasing optical thickness was included in the simulations.

\subsection{Analysis of sensor error}

The total error introduced by a tilted sensor is the sum of the diffuse $\left(\eta_{\text {dif }}\right)$ and direct errors $\left(\eta_{\text {dir }}\right)$, each modified by their respective proportion of diffuse $\left(P_{\mathrm{dif}}\right)$ and $\operatorname{direct}\left(P_{\mathrm{dir}}\right)$ irradiances $\left(P_{\mathrm{dif}}+P_{\mathrm{dir}}=1\right)$ :

$\eta=P_{\mathrm{dir}} \eta_{\mathrm{dir}}+P_{\mathrm{dif}} \eta_{\mathrm{dif}}$

The sensor tilt error $\eta$ is defined as the proportional difference between irradiance as measured by a tilted sensor, $E_{\mathrm{t}}$, and the true irradiance on a horizontal surface, $E_{\mathrm{h}}$ :

$\eta=\frac{E_{\mathrm{t}}-E_{\mathrm{h}}}{E_{\mathrm{h}}}$.

The cosine response of a level irradiance sensor is

$R(\theta)_{\mathrm{h}}^{\mathrm{dir}}=\cos \theta_{0}$,

while the response of a sensor tilted $\theta_{\mathrm{t}}$ degrees at $\phi$ degrees azimuth relative to the sun is

$R(\theta, \phi)_{\mathrm{t}}^{\mathrm{dir}}=\cos \left(\theta_{0}-\theta_{\mathrm{t}} \cos \phi\right)$.

This is of similar form to Eq. (4) in Grenfell et al. (1994), which describes the error in measured albedo incurred when a horizontal measurement is taken over a sloping surface. The measurement error in direct irradiance, $\eta_{\mathrm{dir}}$, is therefore insensitive to wavelength and can be calculated from the three variables: solar zenith angle $\theta_{0}$, sensor tilt $\theta_{\mathbf{t}}$, and relative azimuth $\phi$ :

$\eta_{\text {dir }}=\frac{\cos \left(\theta_{0}-\theta_{\mathrm{t}} \cos \phi\right)-\cos \theta_{0}}{\cos \theta_{0}}$.

The diffuse tilt error of the sensor $\eta_{\text {dif }}$ was calculated (rightmost term in Eq. (8)) by integrating the tilted sensor angular response function across a diffuse radiance distribution and comparing with the result for the leveled sensor (rightmost term in Eq. (7)).

Finally, the analysis addresses the daily integration approach for "averaging out" measurement errors due to tilted sensors (Van den Broeke et al., 2004a; Stroeve et al., 2006). Daily integrated measurements are simply the sum of irradiance measurements integrated over shorter intervals, for example $5 \mathrm{~min}$, over a full day. In this analysis, solar radiation was modeled in $5 \mathrm{~min}$ intervals throughout the day. Irradiances for horizontal and tilted sensors were calculated for each of these solar orientations. Calculations were performed for a sensor tilted $3^{\circ}$ at a fixed azimuth step, iterated around the compass to produce a full day of irradiance 
measurements. The error in the daily integrated irradiance is given by

$\eta=\frac{\sum E_{\mathrm{t}}-\sum E_{\mathrm{h}}}{\sum E_{\mathrm{h}}}$

where it is summed over $24 \mathrm{~h}$.

\section{Results}

We first discuss the significance of the diffuse error $\left(\eta_{\text {dif }}\right)$. Next the proportion variables $(P)$ are explored as functions of solar zenith angle $\left(\theta_{\text {sun }}\right)$ as well as wavelength, including an assessment of integrated visible and global spectra. The total error introduced by non-level sensor orientation is illustrated, in the form presented by Eq. (10). Sensitivity of modeled error to surface albedo and cloudiness, spectral range, as well as effectiveness of daily integration in reducing error are presented in their own subsections.

\subsection{Diffuse component of sensor error: $\eta_{\text {dif }}$}

The diffuse error varies with sensor tilt, relative azimuth, solar zenith angle, and wavelength. The top plot in Fig. 1 illustrates the global diffuse error $\eta_{\text {dif }}$ for a sensor tilted $3^{\circ}$ under a cloudless sky. The diffuse sensor error varies from 0.45 to $1.29 \%$ for a $3^{\circ}$ tilt, while a tilt of 1 and $5^{\circ}$ have an error range of -0.02 to $0.24 \%$ and 1.39 to $3.07 \%$, respectively. For all three tilt angles, variability within the reported range is a function of solar zenith angle and relative azimuth, following similar trends to those illustrated in the top plot of Fig. 1. For most modeled orientations the diffuse error component is positive. A positive diffuse error component means that the tilted sensor reports a higher value of diffuse irradiance than a leveled sensor. Increasing tilt or azimuth angle away from the sun results in a greater magnitude of error, while solar zenith angle has a variable affect.

\subsection{Global error: incorporating $\boldsymbol{P}_{\mathrm{dir}}$ and $\boldsymbol{P}_{\mathrm{dif}}$}

The proportion of direct to diffuse irradiance as viewed by the sensor is also a function of tilt, relative azimuth, solar zenith angle, and wavelength. For all simulated cloudless cases for all solar and sensor orientations, the maximum value of the diffuse error term $P_{\text {dif }} \eta_{\text {dif }}$ is $0.28 \%$ of the true irradiance. This is substantially less than the product of the maximum $P_{\text {dif }}$ and the maximum $\eta_{\text {dif }}$ because these two maxima do not occur at the same solar/sensor orientations and therefore have compensating effects.

Over the same range of solar/sensor orientations, the direct term $P_{\text {dir }} \eta_{\text {dir }}$ varies from 0 to $40.42 \%$ of the true irradiance, with maximum magnitude of error at high solar zenith angle, high tilt, and sensors pointed either directly towards or away from the sun. The total sensor error, presented in Fig. 2, is therefore dominated by the direct term, and varies from 0 to $40.7 \%$.
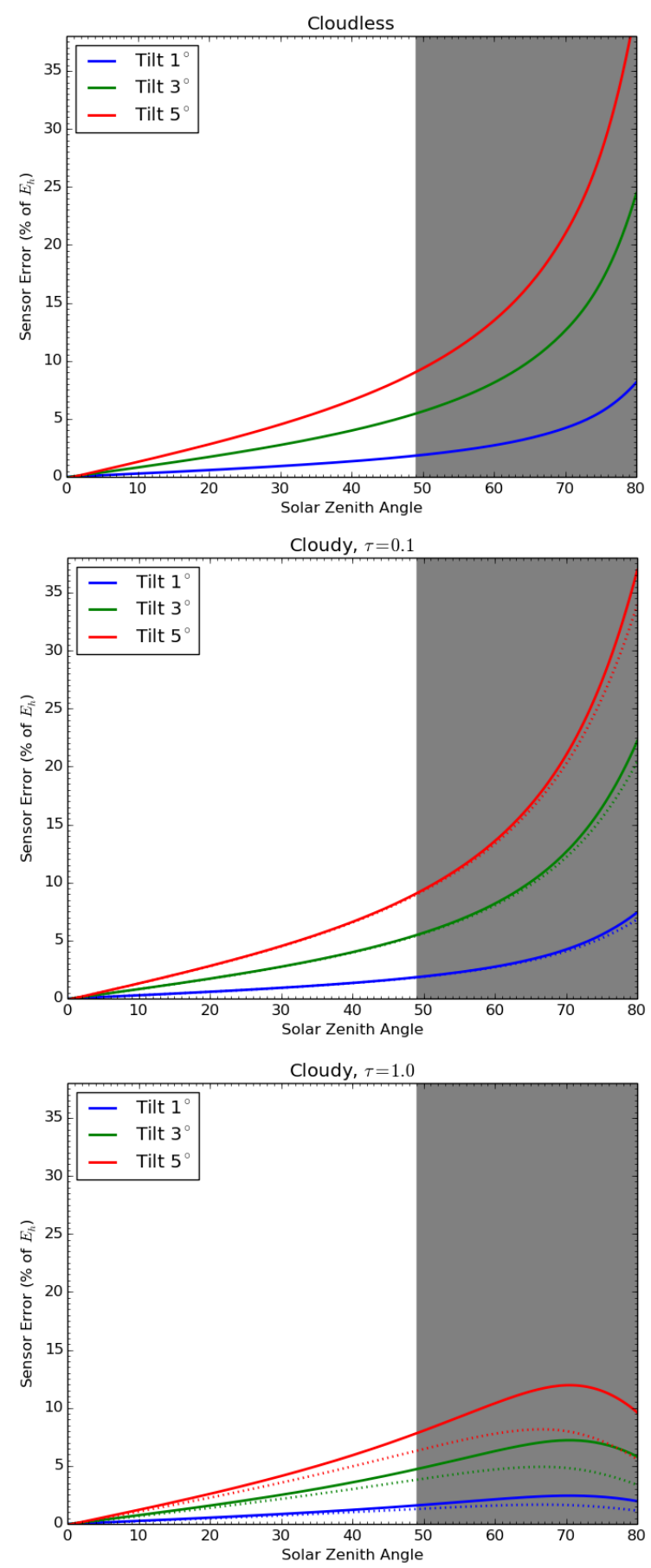

Figure 2. Total sensor error, $\eta$ Eq. (9), for the full solar shortwave spectrum (global), for a sensor tilted directly toward the sun. The same sky conditions are shown as in Fig. 1: one cloudless (top) and two cloudy cases. In the middle and bottom plots, solid (dotted) lines denote liquid (ice) water cloud results. The grey shaded area begins at $49^{\circ}$, representing the lowest observable solar zenith angle at Summit Station, Greenland (latitude $72.58^{\circ}$ ). 
Table 2. The diffuse proportion $\left(P_{\text {dif }}\right)$ of global irradiance. Variability within the ranges presented is a function of sensor pointing azimuth as well as solar zenith angle. The simulations test a range of solar zenith angles from noon $\left(0^{\circ}\right)$ to near-dusk $\left(80^{\circ}\right)$, simulated in $5^{\circ}$ steps.

\begin{tabular}{clll}
\hline Tilt & $(250$ to $4500 \mathrm{~nm})$ & $(250$ to $2500 \mathrm{~nm})$ & $(250$ to $900 \mathrm{~nm})$ \\
\hline $1^{\circ}$ & $8.2-19.4 \%$ & $8.4-19.7 \%$ & $11.9-27.9 \%$ \\
$3^{\circ}$ & $8.3-23.7 \%$ & $8.5-24.1 \%$ & $12.0-33.1 \%$ \\
$5^{\circ}$ & $8.4-30.5 \%$ & $8.5-30.9 \%$ & $12.1-41.3 \%$ \\
\hline
\end{tabular}

\subsection{Model sensitivity: spectral range}

In order to test the spectral sensitivity of the modeled sensor error, three spectral ranges were investigated: the full solar spectrum $(250-4500 \mathrm{~nm})$, a pseudo-visible $(250-900 \mathrm{~nm})$ range, and a visible-infrared $(250-2500 \mathrm{~nm})$ range.

The diffuse error $\eta_{\text {dif }}$, not shown, does not vary dramatically between the simulated spectral ranges, and the direct error $\eta_{\text {dir }}$ is insensitive to wavelength. Therefore variations in the proportional weighting factors $P_{\mathrm{dif}}$ and $P_{\mathrm{dir}}$ are the most significant difference between the three spectral ranges. As summarized in Table 2, the proportion of diffuse irradiance $P_{\text {dif }}$ increases with higher tilt angles and shorter wavelengths.

\subsection{Model sensitivity: surface albedo and homogeneous cloud cover}

In order to test the model sensitivity to variations in surface albedo, the global calculations in Sect. 3.3, with the clean snow albedo from Wiscombe and Warren (1980), were repeated with constant Lambertian albedo values of 0.2 and 0.9. The magnitude of the diffuse error decreases somewhat with lower albedo, but the most significant effect is once again the impact on the diffuse and direct proportional weighting factors, as summarized in Table 3 for $P_{\text {dif. }}$. With higher $P_{\text {dir }}$ over a low albedo surface, the global sensor error $\eta_{\text {glob }}$ is higher. The maximum error $\eta_{\text {glob }}$ for surface albedos of 0.2, 0.9, and pure snow albedo from Wiscombe and Warren (1980), are 42.1, 40.9, and 40.7\%, respectively.

To estimate the effect of clouds on the tilt error, a homogeneous cloud layer was introduced between 4 and $5 \mathrm{~km}$ altitude. Both water and ice clouds were simulated. The water cloud was assumed to consist of water droplets with an effective radius of $10.0 \mu \mathrm{m}$. Water cloud optical properties were taken from the parameterization of Hu and Stamnes (1993). For the ice water cloud simulations the parameterization of Key et al. (2002) was used and the ice particles were assumed to be solid columns. Simulations were made for visible cloud optical depths of 0.1, 1.0, 10.0, and 100.0.

The middle and bottom plots of Figs. 1 and 2 show the global diffuse error and total sensor error, respectively, for cloud optical depths of $\tau=0.1$ and $\tau=1.0$. The global diffuse error increases considerably when introducing an op-
Table 3. Diffuse proportion ( $P_{\text {dif }}$ ) for different surface albedos. The results are for the global $(250$ to $4500 \mathrm{~nm})$, spectral range. Variability within the ranges presented is a function of sensor pointing azimuth as well as solar zenith angle.

\begin{tabular}{llll}
\hline Tilt & $\begin{array}{l}\text { Wiscombe and } \\
\text { Warren (1980) } \\
\text { clean snow }\end{array}$ & Constant albedo & Constant albedo \\
\hline $1^{\circ}$ & $8.2-19.4 \%$ & $7.8-19.0 \%$ & 0.2 \\
$3^{\circ}$ & $8.3-23.7 \%$ & $7.8-23.2 \%$ & $4.1-16.0 \%$ \\
$5^{\circ}$ & $8.4-30.5 \%$ & $7.9-30.0 \%$ & $4.2-25.6 \%$ \\
\hline
\end{tabular}

tically thin cloud layer; compare top and middle plots of Fig. 1. When the cloud becomes optically thicker the error gets smaller; compare middle and bottom plots of Fig. 1. For an optically thin cloud, the radiation is mostly scattered in the forward direction, thus increasing the radiation field around the direction of the sun. As the cloud thickens, multiple scattering increases and the radiation loses all information about its initial direction. Thus, for a cloudless sky the diffuse error is small due to the near-isotropic Rayleigh scattering phase function. For optically thin clouds, the error is large due to the strong forward scattering phase function of the clouds, while for optically thick clouds, multiple scattering becomes important and the error decreases.

For the optically thin cloud $(\tau=0.1)$, the direct radiation still gives the largest contribution to the total sensor error; see middle plot of Fig. 2. For the optically thicker cloud with $\tau=1.0$, the diffuse radiation starts to dominate and the total error gets smaller; see lower plot in Fig. 2. For a cloud with optical depth larger than 10 , the radiation is diffuse and the total sensor error is less than $0.3 \%$ for all solar zenith angles.

\subsection{Daily integrated irradiance}

Error in daily integrated irradiance introduced by $3^{\circ}$ sensor tilt was calculated for 6 days at Summit, Greenland, starting from solstice and continuing to mid-October. The results are valid for observations along the latitude $72.58^{\circ}$. The dates are chosen for the progression of solar zenith at local noon, from $49^{\circ}$ (solstice) through 55, 60, 70, 75, and $80^{\circ}$.

As shown in Fig. 3, the potential error of the integrated measurements is highest when the sensor is tilted due north $\left(0^{\circ}\right)$ or due south $\left(180^{\circ}\right)$, and decreases when the pointing angle is further toward east or west. Within 1 month of solstice, the highest potential error in measured integrated irradiance remains under $1 \%$. However, measurements made more than 2 months (red dashed, dotted line in Fig. 3) from summer solstice by an automatic weather station tilted $3^{\circ}$ due north or south show more than $5 \%$ potential error in daily integrated irradiance. 


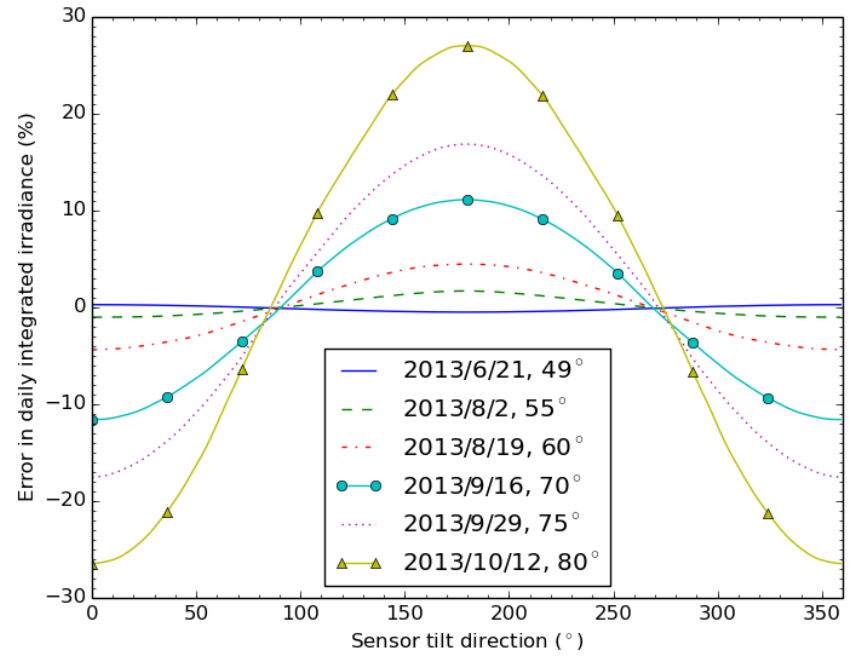

Figure 3. Error in daily integrated irradiance (see Eq. (14)), plotted against sensor tilt azimuth. Dates are chosen to show a local noon solar zenith angle of $49^{\circ}$ (solstice), 55, 60, 70, 75, and $80^{\circ}$, respectively, reading down the legend.

\section{Discussion}

The potential error from sensor orientation has long been recognized (e.g., Van den Broeke et al., 2004a; Stroeve et al., 2005), but methods for addressing the potential error have historically not been described in detail. The long-term instability of towers and weather stations deployed on ice sheets is well documented (e.g., Stroeve et al., 2005, 2006; Van de Wal et al., 2005). In validating MODIS albedo products, Stroeve et al. $(2005$, 2006) did not use AWS data when sensors were discovered during annual site visits to have leveling errors greater than $2^{\circ}$ (Stroeve et al., 2005) and $3^{\circ}$ (Stroeve et al., 2006); the smaller leveling errors were addressed by using integrated daily albedo.

For realistic scenarios we have shown that the potential error in measured irradiance from a slight misalignment and leveling of the instrument may be greater than $2 \%$, and in some cases, much greater. However, the error varies over a broad range with the azimuth of the tilt, as well as variations in surface albedo and atmospheric conditions which can affect the proportions of diffuse and direct irradiances. This was exemplified by the study of Kreuter et al. (2014) who compared several UV and visible spectrometer measurements at a coastal site in the Arctic with a detailed 3$\mathrm{D}$ version of the radiative transfer model used in the present study. Besides changes in drift ice, aerosol, and distant high clouds, a detector tilt of about $1^{\circ}$ was one of the plausible explanations for the differences between measurements and simulations.

Small leveling errors are extremely difficult to prevent when instruments are mounted on snow and ice. Accurate in situ measurements of albedo are important for validation of satellite products and input for climate models. For more recent applications such as attempting to estimate concentrations of aerosols and impurities deposited in the upper layer of a snowpack, it is critical that remaining sources of significant uncertainty are identified and addressed. Therefore, while existing measurements may or may not include components from this error source, it does represent a significant source of uncertainty that must be addressed for applications of albedo observations in polar regions. It is not suggested that every measurement from a sensor which may have been tilted is subject to the maximum potential error; nor is it even suggested that existing measurements are too greatly influenced by this error to be useful. We do, however, recommend greater care be placed into the leveling of measurements and feel hand-leveled observations (e.g., on a handheld extension) are prone to larger errors than operators may expect.

With a precise record of sensor orientation, the potential error of a measurement can be estimated. However, sensors for monitoring orientation would add complications to design and deployment, especially for short-term measurements. They are not typically integrated in the design of equipment for field campaigns, nor towers or automatic weather stations. Given the magnitude of potential error involved and the desired accuracy of measurements, this practice should be reconsidered. Knowledge of the sensor orientation may still not make it simple to fully correct the error unless a complete record of sky conditions is available, including ozone absorption in the UV, optical depths of significant aerosols, and single scattering albedo. For scattered clouds, a 3-D radiative transfer model may be needed. Due to these challenges in applying accurate corrections, emphasis should be placed on recognizing the level of uncertainty introduced by a misaligned sensor, and taking every step to minimize errors in alignment. It is furthermore critical to maintain a precise log of sensor orientation in order to quantify firm boundaries on the uncertainty of a measurement. Potential errors due to tilt problems are also reduced by making measurements which integrate over short intervals close to noon, and for daily integrated values around summer solstice.

Any tilt correction method will depend on the information available about tilt and rotation of the instrument. Furthermore, the tilt correction will depend on the state of the atmosphere. The need and importance of tilt correction depends on the use of the data. Satellite validation requires cloud-free data for which the tilt error is one of the major uncertainties and reaches a maximum. For studies including all weather data the cloudy data will be less affected by tilt errors.

In the case where no information is available about tilt or orientation and the state of the atmosphere, $24 \mathrm{~h}$ running averages have been used by several authors, including Van den Broeke et al. (2004b) and Stroeve et al. (2013). While this approach may intuitively be appealing it will miss any daily variation in the surface albedo and, as shown above, may, for example, give errors around $\pm 5 \%$ for sensor tilts of $3^{\circ}$ 
for Summit, Greenland, over a 2 month period around solstice. These shortcomings are largest for a cloudless sky and $24 \mathrm{~h}$ running averages may be justified under stable cloud conditions. If tilt and rotation information is available, this may be used to correct the downwelling shortwave radiation. Using inclinometer and compass information Van As (2011) tilt-corrected the direct component of the downwelling shortwave radiation. Wang et al. (2015) recently presented a retrospective iterative geometry-based tilt correction method. For cloudless sky measurements the tilt and rotation angles are estimated by finding the modeled insolation for various tilt and rotation angles that best agrees with the measured insolation. The estimated tilt and rotation angles may subsequently be used to correct both cloudless and cloudy measurement data. Wang et al. (2015) show that this tilt correction method gives lower biases both for unadjusted measurements and also for measurements tilt-adjusted using inclinometer information. This method requires no extra measurements of tilt and orientation to be made. It may thus be used for all past radiation measurements where such information is not available. Another tilt correction method was presented by Weiser et al. (2015). It, however, requires data from a nearby leveled sensor, and as such is not applicable for most long-term installations such as AWS stations.

The simulations presented here demonstrate that the impact of the tilt error is largest for cloudless skies. It is also these measurement conditions that are used for satellite validation. The impact of the tilt error decreases in the presence of increasingly optically thicker clouds. This is caused by changes in the ratio of diffuse versus global radiation. Tilt correction methods that rely on knowledge about this ratio may benefit from the estimates of this ratio.

AWS stations provide long-term records of essential climate variables. As such, methods to correct past, present, and future data where limited ancillary information is available, is of great value. The method presented by Wang et al. (2015) may be used for this purpose. It does require assumptions about the cloud fraction. An alternative sequence for estimating the cloud fraction may be to (1) identify truly cloudless data to obtain tilt information using the RIGB method; (2) calculate albedo for the cloudless days; (3) for cloudy days use a method similar to Stamnes et al. (1991) to obtain estimate of cloud optical depth (and hence indirectly cloud fraction); and (4) perform tilt correction for cloudy days based on tilt information from (1) and cloud fraction from (3). For future instrument deployments, it may be worthwhile also considering increasing the time resolution of reported data, if feasible, to provide more data to the RIGB and other tilt correction methods.

\section{Conclusions}

Non-level irradiance measurements can result from a tilted or slowly shifting sensor installed over a snow surface or a rapidly shifting sensor mounted on a mobile platform. We have evaluated the error in irradiance measurements and corresponding albedo estimates due to sensor tilt, with a focus on high latitudes. For a cloudless sky, the diffuse error, $\eta_{\text {dif }}$, due to the diffuse irradiance is of minimal importance as it is consistently low, varying between -0.02 and $3.07 \%$ for all simulated geometries and model parameters. The total diffuse error term is reduced to $0.28 \%$ due to the proportion of diffuse and direct radiation, $P_{\mathrm{dif}}$. By contrast the direct error, $\eta_{\mathrm{dir}}$, varies from 0 to $50 \%$, reduced by direct proportion $P_{\text {dir }}$ to a maximum $40.42 \%$. The simplest method for estimating sensor error is therefore $P_{\mathrm{dir}} \eta_{\mathrm{dir}}$, which deviates less than $0.28 \%$ from the total sensor error for a clear polar atmosphere. The direct error $\eta_{\text {dir }}$ can be calculated directly using Eq. (5) when the sensor and solar geometries are known, but $P_{\text {dir }}$ must be measured or modeled.

The total error in irradiance, and hence albedo measurements due to tilt errors, increases with increasing solar zenith angles. For a solar zenith angle of $60^{\circ}$, a sensor tilt of 1,3 , and $5^{\circ}$ can introduce up to $2.7,8.1$, and $13.5 \%$ error, respectively, in the measured irradiance and derived albedo. The corresponding numbers for a solar zenith angle of $70^{\circ}$ are $4.2,12.6$, and $20.9 \%$. Integrating measurements over the day decreases these numbers to a maximum of about $\pm 4 \%$ $(11 \%)$ for a tilt of $3^{\circ}$ and solar zenith angle at noon of $60^{\circ}$ $\left(70^{\circ}\right)$.

Simulations including a cloud layer demonstrate that the tilt error decreases with increasing cloud optical depth. For solar zenith angles above about $60^{\circ}$, the use of a cloudless correction may overestimate the correction when the sky has a optically thin cloud layer (haze). Hence, knowledge about the presence of thin clouds may improve cloud correction methods under these sky conditions. For optically thick clouds the correction is negligible.

The present results demonstrate that tilt information and/or tilt correction methods are needed in order to improve the surface irradiance and albedo data sets used in climate studies and to validate satellite retrievals. Tilt information would make it possible to determine an upper bound for the measurement uncertainty due to tilt error. Such uncertainty estimates due to tilt error should be included in the uncertainty estimates of the measured quantity.

The measurements made by the AWS stations are extremely important to follow the changing climate. As such increased understanding of the importance and quantification of the tilt error is warranted. Thus, a dedicated validation study for various tilt angles under a high sun and high albedo is warranted. Such a study should also include the testing and validation of tilt correction methods.

Acknowledgement. This work was conducted within the Norwegian Research Council's NORKLIMA program under the Variability of Albedo Using Unmanned Aerial Vehicles (VAUUAV) project (NFR no. 184724), Hydrologic sensitivity to CryosphereAerosol interaction in Mountain Processes (HyCAMP) project 
(NFR no. 222195), and the Remote Imaging and Spectral Characterization of the Cryosphere (RISCC) project (NFR no. 196204). The authors would also like to acknowledge the constructive comments received during review from C. Zender, D. van As, and an anonymous reviewer.

Edited by: C. Duguay

\section{References}

Anderson, G., Clough, S., Kneizys, F., Chetwynd, J., and Shettle, E.: AFGL atmospheric constituent profiles (0-120 km), Hansom AFB, Bedford, MA, 1986.

Aoki, T., Aoki, T., Fukabori, M., Hachikubo, A., Tachibana, Y., and Nishio, F.: Effects of snow physical parameters on spectral albedo and bidirectional reflectance of snow surface, J. Geophys. Res., 105, 10219-10236, 2000.

Augustine, J. A., DeLuisi, J. J., and Long, C. N.: Surfrad - a national surface radiation budget network for atmospheric resarch, B. Am. Meteorol. Soc., 81, 2341-2357, 2000.

Bais, A. F., Kazadzis, S., Balis, D., Zerefos, C. S., and Blumthaler, M.: Correcting global solar ultraviolet spectra recorded by a brewer spectroradiometer for its angular response error, Appl. Optics, 37, 6339-6444, 1998.

Bernhard, G. and Seckmeyer, G.: Uncertainty of measurements of spectral solar UV irradiance, J. Geophys. Res., 104, 1432114345, 1999.

Buras, R., Dowling, T., and Emde, C.: New secondary-scattering correction in DISORT with increased efficiency for forward scattering, J. Quant. Spectrosc. Ra., 112, 2028-2034, 2011.

Dahlback, A. and Stamnes, K.: A new spherical model for computing the radiation field available for photolysis and heating at twilight, Planet. Space Sci., 39, 671-683, 1991.

Emde, C., Buras-Schnell, R., Kylling, A., Mayer, B., Gasteiger, J., Hamann, U., Kylling, J., Richter, B., Pause, C., Dowling, T., and Bugliaro, L.: The libRadtran software package for radiative transfer calculations (Version 2.0), Geosci. Model Dev. Discuss., 8, 10237-10303, doi:10.5194/gmdd-8-10237-2015, 2015.

Gardner, A. S. and Sharp, M. J.: A review of snow and ice albedo and the development of a new physically based broadband albedo parameterization, J. Geophys. Res., 115, 1-15, 2010.

Grenfell, T. C., Warren, S. G., and Mullen, P. C.: Reflection of solar radiation by the Antarctic snow surface at ultraviolet, visible, and near-infrared wavelengths, J. Geophys. Res., 99, 18669-18684, 1994.

$\mathrm{Hu}$, Y. X. and K. Stamnes.: An accurate parameterization of the radiative properties of water clouds suitable for use in climate models, J. Climate, 6, 728-742, 1993.

Kato, S., Ackerman, T. P., Mather, J. H. and Clothiaux, E. E.: The kdistribution method and correlated-k approximation for a shortwave radiative transfer model, J. Quant. Spectrosc. Ra., 62, 109121, 1999.

Key, J. R., Yang, P., Baum, B. A., and Nasiri, S. L.: Parameterization of shortwave ice cloud optical properties for various particle habits, J. Geophys. Res., 107, D13, doi:10.1029/2001JD000742, 2002 .
Klein, A. G., and Stroeve, J.: Development and validation of a snow albedo algorithm for the MODIS instrument, Ann. Glaciol., 34, 45-52, 2002.

Kreuter, A., Buras, R., Mayer, B., Webb, A., Kift, R., Bais, A., Kouremeti, N., and Blumthaler, M.: Solar irradiance in the heterogeneous albedo environment of the Arctic coast: measurements and a 3-D model study, Atmos. Chem. Phys., 14, 59896002, doi:10.5194/acp-14-5989-2014, 2014.

Liang, S.: Narrowband to broadband conversions of land surface albedo I Algorithms, Remote Sens. Environ., 76, 213-238, 2001.

Long, C. N., Bucholtz, A., Jonsson, H., Schmid, H., Vogelmann, A., and Wood, J.: A method of correcting for tilt from horizontal in downwelling shortwave irradiance measurements on moving platforms, Open Atmos. Sci. J., 4, 78-87, 2010.

Mayer, B. and Kylling, A.: Technical note: The libRadtran software package for radiative transfer calculations - description and examples of use, Atmos. Chem. Phys., 5, 1855-1877, 2005.

Nicolaus, M., Hudson, S. R., Gerland, S., and Munderloh, K.: A modern concept for autonomous and continuous measurements of spectral albedo and transmittance of sea ice, Cold Reg. Sci. Technol., 62, 14-28, 2010.

Oerlemans, J. and Klok, E. J.: Energy balance of a glacier surface: analysis of automatic weather station data from the Morteratschgletscher, Switzerland, Arct. Antarct. Alp. Res., 34, 477485, 2002.

Perovich, D. K., Grenfell, T. C., Light, B., and Hobbs, P. V.: Seasonal evolution of the albedo of multiyear Arctic sea ice, J. Geophys. Res., 107, 1-13, 2002.

Sellers, P. J., Meeson, B. W., Hall, F. G., Asrar, G., Murphy, R. E., Schiffer, R. A., Bretherton, F. P., Dickinson, R. E., Ellingson, R. G., Field, C. B., Huemmrich, K. F., Justice, C. O., Melack, J. M., Roulet, N. T., Schimel, D. S., and Try, P. D.: Remote sensing of the land surface for studies of global change: models - algorithms - experiments, Remote Sens. Environ., 51, 3-26, 1995.

Stamnes, K., Tsay, S.-C., Wiscombe, W., and Jayaweera, K.: Numerically stable algorithm for discrete-ordinate-method radiative transfer in multiple scattering and emitting layered media, Appl. Optics, 27, 2502-2509, 1988.

Stamnes, K., Slusser, J., and Bowen, M.: Derivation of total ozone abundance and cloud effects from spectral irradiance measurements, Appl. Opt., 30, 4418-4426, 1991.

Steffen, K. and Box, J.: Surface climatology of the Greenland ice sheet: Greenland climate network 1995-1999, J. Geophys. Res., 106, 33951-33964, 2001.

Stroeve, J.-C., Nolin, A., and Steffen, K.: Comparison of AVHRRderived and in situ surface albedo over the Greenland Ice Sheet, Remote Sens. Environ., 62, 262-276, 1997.

Stroeve, J.-C., Box, J. E., Fowler, C., Haran, T., and Key, J.: Intercomparison between in situ and AVHRR polar pathfinder-derived surface albedo over greenland, Remote Sens. Environ., 75, 360 374, 2001.

Stroeve, J.-C., Box, J. E., Gao, F., Liang, S., Nolin, A., and Schaaf, C.: Accuracy assessment of the MODIS 16-day albedo product for snow: comparisons with Greenland in situ measurements, Remote Sens. Environ., 94, 46-60, 2005.

Stroeve, J.-C., Box, J. E., and Haran, T.: Evaluation of the MODIS (MOD10A1) daily snow albedo product over the Greenland ice sheet, Remote Sens. Environ., 105, 155-171, 2006. 
Stroeve, J., Box, J. E., Wang, Z., Schaaf, C., and Barrett, A.: Reevaluation of \{MODIS \} \{MCD43\} Greenland albedo accuracy and trends, Remote Sens. Environ., 138, 199-214, 2013.

Svacina, N. A., Duguay, C. R. and King,J. M. L.: Modelled and satellite-derived surface albedo of lake ice - Part II: evaluation of MODIS albedo products, Hydrol. Proc., 28, 4562-4572, 2014.

van Angelen, J. H., Lenaerts, J. T. M., Lhermitte, S., Fettweis, X., Kuipers Munneke, P., van den Broeke, M. R., van Meijgaard, E., and Smeets, C. J. P. P.: Sensitivity of Greenland Ice Sheet surface mass balance to surface albedo parameterization: a study with a regional climate model, The Cryosphere, 6, 1175-1186, doi:10.5194/tc-6-1175-2012, 2012.

Van As, D.: Warming, glacier melt and surface energy budget from weather station observations in the Melville Bay region of northwest Greenland, J. Glaciol., 57, 208-220, 2011.

Van de Wal, R. S. W., Greuell, W., Van den Broeke, M. R., Reijmer, C. H., and Oerlemans, J.: Surface mass-balance observations and automatic weather station data along a transect near Kangerlussuaq, West Greenland, Ann. Glaciol., 42, 311-316, 2005.

Van den Broeke, M., Van As, D., Reijmer, C., and Van de Wal, R.: Assessing and improving the quality of unattended radiation observations in Antarctica, J. Atmos. Ocean. Tech., 21, 1417-1431, 2004a.
Van den Broeke, M., Reijmer, C., and van de Wal, R.: Surface radiation balance in Antarctica as measured with automatic weather stations, J. Geophys. Res., 109, D09103, doi:10.1029/2003JD004394, 2004b.

Wang, W., Zender, C. S., van As, D., Smeets, P. C. J. P., and van den Broeke, M. R.: A Retrospective, Iterative, GeometryBased (RIGB) tilt correction method for radiation observed by Automatic Weather Stations on snow-covered surfaces: application to Greenland, The Cryosphere Discuss., 9, 6025-6060, doi:10.5194/tcd-9-6025-2015, 2015.

Weiser, U., Olefs, M., Schöner, W., Weyss, G., and Hynek, B.: Correction of albedo measurements due to unknown geometry, The Cryosphere Discuss., 9, 2709-2744, doi:10.5194/tcd-92709-2015, 2015.

Wiscombe, W. J. and Warren, S. G.: A model for the spectral albedo of snow - Part I: Pure snow, J. Atmos. Sci., 37, 2712-2733, 1980. 